Metal-Catalyzed

Asymmetric

Synthesis and

Stereoselective

Reactions

\section{Asymmetric Rhodium-Catalyzed Synthesis of Tertiary Propargyl Alcohols}
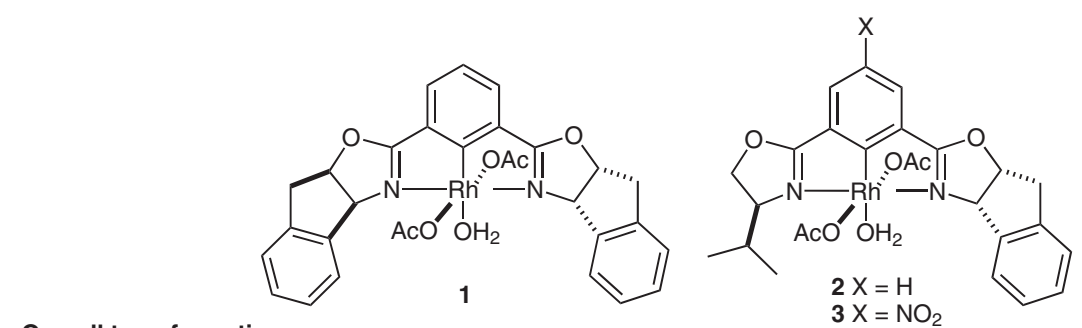

Overall transformation:

$3 \mathrm{X}=\mathrm{NO}_{2}$

\section{Key words}

asymmetric alkynylation

rhodium catalysis

$C_{1}$-symmetric Phebox ligands

chiral propargyl alcohols

$\alpha$-keto esters

Selected substrate scope:

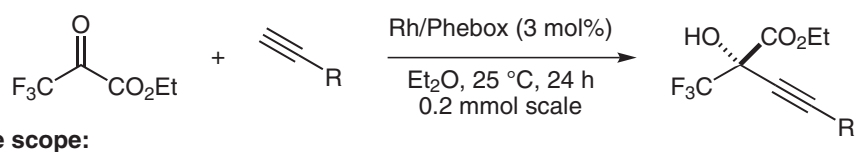

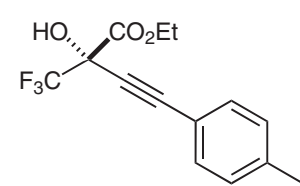

$182 \%$ yield, $95 \%$ ee 2 90\% yield, $94 \%$ ee<smiles>CCOC(=O)C(O)(C#Cc1ccc(OC)cc1)C(F)(F)F</smiles>

$178 \%$ yield, $80 \%$ ee $288 \%$ yield, $90 \%$ ee

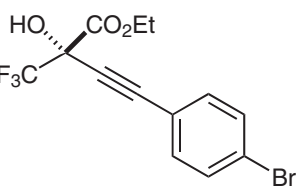

$186 \%$ yield, $94 \%$ ee $289 \%$ yield, $95 \%$ ee

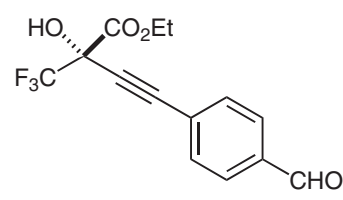

$283 \%$ yield, $89 \%$ ee<smiles>CCOC(O)(C#CCCc1ccccc1)C(F)(F)F</smiles>

3 91\% yield, $92 \%$ ee<smiles>CCOC(O)(C#CC1=CCCCC1)C(F)(F)F</smiles>

3 93\% yield, $96 \%$ ee

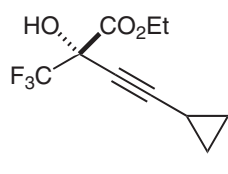

$397 \%$ yield, $74 \%$ ee

Proposed catalytic cycle:

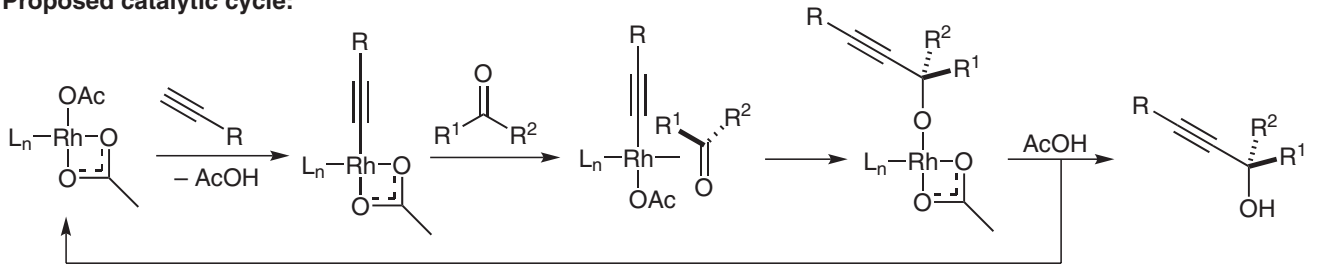

Significance: In contrast to the results of reacting aldehydes, there have been a limited number of examples that demonstrate a chemoselective and highly asymmetric alkynylation of ketones. The authors report a Rh/Phebox-catalyzed alkynylation of $\alpha$-keto esters. A variety of alkynes are utilized in generally good yields with good to excellent enantioselectivities.
Comment: A highly enantioselective Rh/Pheboxcatalyzed process is reported for the synthesis of chiral tertiary propargyl alcohols. Yields are generally good to excellent and enantioselectivities are generally moderate to excellent. The chemoselective nature of this reaction is particularly noteworthy, as aldehydes and other functional groups are tolerated.

SYNFACTS Contributors: Mark Lautens, Hasnain A. Malik 